Tropical Journal of Pharmaceutical Research June 2019; 18 (6): 1291-1296

ISSN: $1596-5996$ (print); 1596-9827 (electronic)

(C) Pharmacotherapy Group, Faculty of Pharmacy, University of Benin, Benin City, 300001 Nigeria.

\title{
GC-MS analysis of essential oil from Anethum graveolens L (dill) seeds extracted by supercritical carbon dioxide
}

\author{
Hongbo $\mathrm{Li}^{1-3}$, Wei $\mathrm{Zhou}^{3}$, Yongshuai $\mathrm{Hu}^{4}$, Haizhen $\mathrm{Mo}^{3}$, Jinshui Wang ${ }^{1}$, Liangbin \\ $\mathrm{Hu}^{3 *}$ \\ ${ }^{1}$ College of Food Science and Technology, Henan University of Technology, Zhengzhou 450001, ${ }^{2}$ Postdoctoral Research Base, \\ ${ }^{3}$ School of Food Science, Henan Institute of Science and Technology, Xinxiang 453003, ${ }^{4}$ College of Food Science and \\ Technology, Henan Agricultural University, Zhengzhou 450001, China
}

*For correspondence: Email: lihongbo@hist.edu.cn

Sent for review: 3 October 2019

Revised accepted: 23 May 2019

\begin{abstract}
Purpose: To conduct gas chromatography-mass spectrometric (GC-MS) analysis of the chemical compositions of dill seed essential oil (DSEO) obtained by supercritical $\mathrm{CO}_{2}$.

Methods: The impact on extraction yield were examined by single factor test, the particle size of dill seed, extraction temperature, time, pressure, as well as $\mathrm{CO}_{2}$ flux. The best extraction conditions were obtained by an orthogonal test. The chemical configurations of essential oil were examined by GC-MS analysis.

Results: The optimal extraction conditions included an extraction time of 120 min, particle size of 60 mesh, $\mathrm{CO}_{2}$ flow of $25 \mathrm{~L} / \mathrm{h}$, temperature of $40^{\circ} \mathrm{C}$, and pressure of $20 \mathrm{MPa}$. Under these conditions, the yield of essential oil was $6.7 \%$. Out of 38 recognized compounds, the main ones were D-carvone (40.36\%), D-limonene (19.31\%), apiol (17.50\%), a-pinene (6.43\%), 9-octadecenoic acid (9.00\%) as well as 9,12-octadecadienoic acid (2.44\%).

Conclusion: $A$ total of 38 constituents of the essential oil obtained by supercritical $\mathrm{CO}_{2}$ were identified. The findings may provide a theoretical basis for comprehensive utilization of dill seed essential oil (DSEO) from China.
\end{abstract}

Keywords: Dill seeds, Essential oil, Supercritical $\mathrm{CO}_{2}$ extraction, D-Carvone, D-Limonene, Apiol, $\alpha$ Pinene, 9-Octadecenoic acid

\begin{abstract}
This is an Open Access article that uses a fund-ing model which does not charge readers or their institutions for access and distributed under the terms of the Creative Commons Attribution License (http://creativecommons.org/licenses/by/4.0) and the Budapest Open Access Initiative (http://www.budapestopenaccessinitiative.org/read), which permit unrestricted use, distribution, and reproduction in any medium, provided the original work is properly credited.

Tropical Journal of Pharmaceutical Research is indexed by Science Citation Index (SciSearch), Scopus, International Pharmaceutical Abstract, Chemical Abstracts, Embase, Index Copernicus, EBSCO, African Index Medicus, JournalSeek, Journal Citation Reports/Science Edition, Directory of Open Access Journals (DOAJ), African Journal Online, Bioline International, Open-J-Gate and Pharmacy Abstracts
\end{abstract}

\section{INTRODUCTION}

Dill is widely cultivated in India, the Middle East, Russia, Egypt, Thailand, and China, where its leaves and seeds are used as an herb or spice for flavoring food. Matured dill seeds are rich in right-hand carvone, limonene, and apopinol and are commonly used to extract essential oil. As a broad-spectrum antifungal agent for many kinds of food spoilage fungi, DSEO has been widely used in food preservation and pharmaceuticals [1].

The chemical composition of DSEO varies depending on different geographic origins. The main chemical composition and relative content 
of essential oil, extracted from Xinjiang dill by steam distillation, are pentadecane (27.96\%), dioctyl-1,2-two-phenyl hydroxylate (25.10\%), octacosane (13.81\%), and tricosane (9.41\%). Moreover, the corresponding content of carvone and limonene are $2.12 \%$ and $1.68 \%$ [2]. Thirtyfive components have been identified from DSEO extracted from Indian dill with the same method. The main components of DSEO are carvone (55.2\%), limonene (16.6\%), apopinol (14.4\%), as well as linalool (3.7\%) [3]. Different chemical compositions can also alter the biological activity of essential oil, therefore, it is necessary to study the DSEO from different regions.

Essential oils have been conventionally extracted using techniques for instance hydrodistillation, steam distillation, solvent extraction, cold pressing, as well as simultaneous distillationextraction methods, among others [4]. The disadvantages of these common methods are low efficiency, longer time duration, thermal degradation, loss of volatiles, and solvent residue $[5,6]$. The supercritical fluid extraction technique has been studied extensively as a promising alternative to conventional methods of extraction as it offers many advantages [7]. $\mathrm{CO}_{2}$ is usually the most preferred solvent as it is nonhazardous, easily available, inexpensive, and fire-resistant with little critical point necessities for temperature and pressure [8].

The optimization of the supercritical $\mathrm{CO}_{2}$ process for DSEO was studied in this paper. The extraction yield of DSEO was discussed by using single factor test and orthogonal array experiments. The main compounds of DSEO were analyzed by GC-MS. This study may provide a theoretical basis for comprehensive utilization of DSEO from China.

\section{EXPERIMENTAL}

\section{Materials and chemicals}

Dill seeds were purchased from Lanzhou Baihe (Gansu Winshine Metallurgy Chemicals Co., Ltd, China) in 2016. The whole seeds $(<4 \mathrm{~mm})$ were using a crusher (JHF-500A, Juhongfeng, China). The crushed powder was forced through a sieve, resulting in powder with a range of particle sizes [9]. Crushed powder of various particle sizes was acquired by grinding the seeds and sieving the material attained. Carbon dioxide (purity $99.9 \%$ ) and helium (purity $99.9 \%$ ) were supplied by Zhibao Co. Ltd. (Xinxiang, China). Analyticalgrade chemicals were used for all experiments.

\section{Optimization of supercritical $\mathrm{CO}_{2}$ extraction of DSEO}

A laboratory scale supercritical fluid extraction system (Aerospace Wujiang Electromechanical Equipment Co., Ltd., Guizhou, China) was used in the experiments for extraction of DSEO. The effects on the extraction yield of DSEO under various extraction situations, such as the particle size of raw materials, the extraction pressure, temperature, $\mathrm{CO}_{2}$ flux, and the extraction time, were discussed to find the optimum parameters $[6,10]$. The single factor test was used in a series of experiments by keeping other factors constant in the optimization experiments.

As per the associated literature as well as the results of initial tests $[1,11]$, the particle size of raw materials was set to $20,40,60,80,100$ mesh, the extracting temperature was $30,35,40$, 45 , and $50{ }^{\circ} \mathrm{C}$, the extracting pressure was 20 , 22, 24, 26 and $28 \mathrm{MPa}$, the extracting time was $30,60,90,120$ and $150 \mathrm{~min}$, and the $\mathrm{CO}_{2}$ flow rate was $15,20,25,30$ and $35 \mathrm{~L} / \mathrm{h}$. Then, an orthogonal design $\left[\mathrm{L}_{16}\left(4^{5}\right)\right]$ was used to improve the extraction situations. Table 1 provides the factor-level list of the orthogonal test was shown in Table 1. The yield of oil extract was used as the evaluation index, which was defined as the mass of extracted DSEO per $100 \mathrm{~g}$ of wet feed material.

Table 1: Factors and levels of the orthogonal experiment

\begin{tabular}{lcccc}
\hline $\begin{array}{l}\text { Particle } \\
\text { size } \\
\text { (mesh) }\end{array}$ & $\begin{array}{c}\text { Temp } \\
(\mathrm{oC})\end{array}$ & $\begin{array}{c}\text { Pressure } \\
\text { (MPa) } \\
\text { B }\end{array}$ & $\begin{array}{c}\text { Time } \\
\text { (min) } \\
\text { D }\end{array}$ & $\begin{array}{c}\mathbf{C O}_{2} \text { flow } \\
(\mathbf{L} / \mathbf{h}) \\
\text { E }\end{array}$ \\
\hline 40 & 35 & 20 & 30 & 15 \\
60 & 40 & 22 & 60 & 20 \\
80 & 45 & 24 & 90 & 25 \\
100 & 50 & 26 & 120 & 30 \\
\hline
\end{tabular}

\section{GC-MS analysis of DSEO}

Qualitative analysis of DSEO was done using GC-MS (7890B GC/5977A MSD, Agilent Technology, CA, USA), combined to a 5972 mass selective detector. The oven temperature was set at $50{ }^{\circ} \mathrm{C}$ for $2 \mathrm{~min}$, augmented to $150{ }^{\circ} \mathrm{C}$ at a rate of $2{ }^{\circ} \mathrm{C} / \mathrm{min}$, and then augmented to 280 ${ }^{\circ} \mathrm{C}$ for $2 \mathrm{~min}$. The split ratio was $5: 1$ at the GC front inlet. The carrier gas was helium with a flow rate of $1 \mathrm{~mL} / \mathrm{min} .1 \mu \mathrm{L}$ of each sample was injected. For the detection of the peaks in the chromatograms, the probability-based matching algorithm was applied to find the utmost prospective match in the NIST library. The relative composition of the components present 
in DSEO was calculated from the GC peak area [12].

\section{Statistical analysis}

SPSS (IBM, version 23) and Origin (9.1) were used for statistical analysis. Two-way ANOVA was utilized to assess the differences among groups [13]. The significance level was set at the $95 \%$ confidence level with $p<0.05$.

\section{RESULTS AND DISCUSSION}

\section{Effect of particle size on yield of oil extract}

The effect of particle size on Supercritical $\mathrm{CO}_{2}$ extraction of DSEO was tested using the ground powder of different particle sizes. Extracting temperature and pressure were kept constant at $45^{\circ} \mathrm{C}$ and $24 \mathrm{MPa}$, respectively. The extraction time was $90 \mathrm{~min}$. The $\mathrm{CO}_{2}$ flow rate was fixed at $15 \mathrm{~L} / \mathrm{h}$.

The results are shown in Figure $1 \mathrm{~A}$. Within a certain range, the yield of DSEO was increased with decreasing particle size. However, the particle size was so small that it clogged the screen, and the flow rate of the supercritical fluid was declined. When the particle size was $<60$ mesh, the extracting ratio decreased. Hence, the best value for particle size was 60 mesh.

\section{Effect of extraction temperature on oil yield}

The extracting temperature was set at $30,35,40$, 45 and $50{ }^{\circ} \mathrm{C}$, with other conditions unchanged. Particle size was 60 mesh. It was concluded that as the temperature increased, the yield of DSEO also increased (Figure $1 \mathrm{~B}$ ). However, But the upward trend flattened when the temperature was higher than $50{ }^{\circ} \mathrm{C}$. and because of this, the higher temperature increased the vapor pressure and diffusion coefficient. Hence, the best value for the extracting temperature was $45^{\circ} \mathrm{C}$.

\section{Effect of extraction pressure on oil yield}

The extracting pressure was set at 20,22, 24, 26 and $28 \mathrm{MPa}$, with other conditions unchanged. As shown in Figure $1 \mathrm{C}$, the yield of DSEO increased with pressure, but the upward trend flattened when the pressure increased constantly. Due to this occurrence, the main composition of DSEO is volatile oils easily soluble in supercritical $\mathrm{CO}_{2}$. The content of the nonvolatile component was low so that the yield increased by a small amount as the pressure increased. Taking compression resistance and product cost into account, the best extracting pressures were between 24 and $26 \mathrm{MPa}$.

\section{Effect of extraction time on oil yield}

When the extraction time exceeded 90 minutes, the yield of DSEO increased slowly and there was not any substantial difference (Figure 1D). Therefore, the extraction times of $30,60,90,120$ min can be used as the four-levels of orthogonal test on the temperature factor.

\section{Effect of $\mathrm{CO}_{2}$ flow on oil yield}

The $\mathrm{CO}_{2}$ flow was set at $15,20,25,30$ and 35 $\mathrm{L} / \mathrm{h}$, with other conditions unchanged. As shown in Figure $1 \mathrm{~F}$, the yield of DSEO increased with the $\mathrm{CO}_{2}$ flow. When extraction time exceeded 25 $\mathrm{L} / \mathrm{h}$, the yield of DSEO stayed flat. The increase in the $\mathrm{CO}_{2}$ flow increased the mass transfer driving force and solvent ratio during the extraction process. The dissolution rate of the soluble matter was accelerated and the extraction efficiency was improved. However, a solvent flow that is too fast will only increase the consumption of carbon dioxide and energy consumption. Taking compression resistance and product cost into account, 15, 20, 25 and 30 $\mathrm{L} / \mathrm{h}$ were chosen as the four-levels of the orthogonal test on the $\mathrm{CO}_{2}$ flow factor.
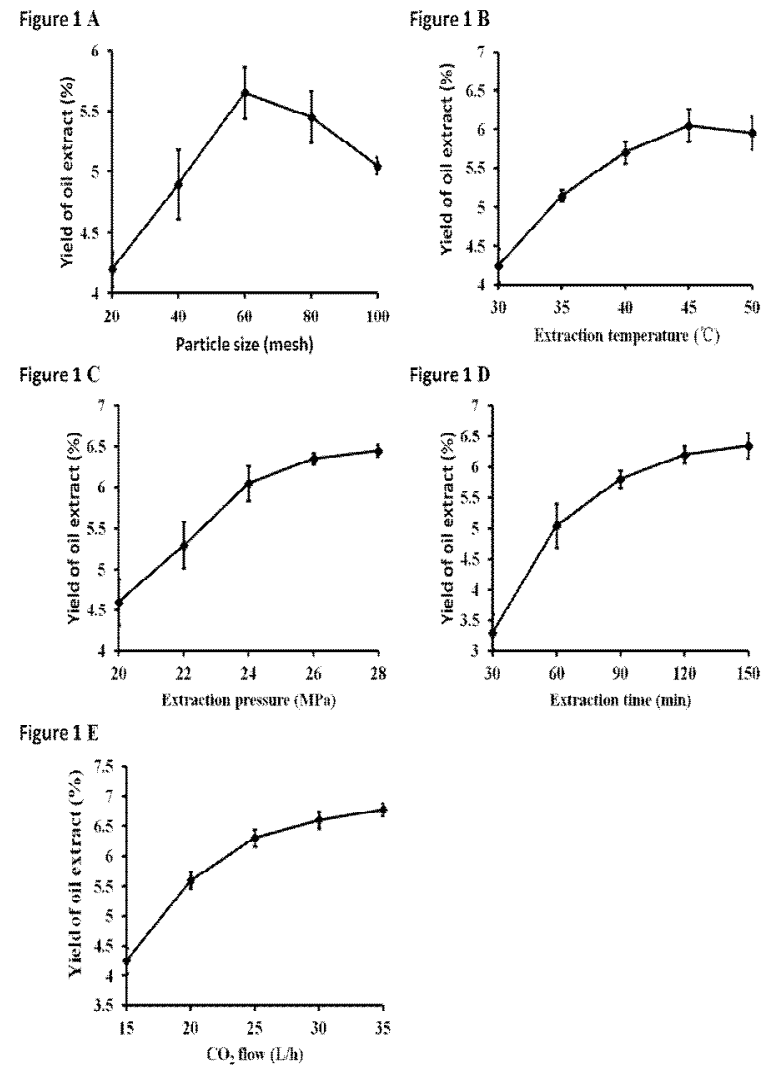

Figure 1: Effect of various operating factors on the extraction of DSEO 


\section{Orthogonal array}

In a series of experiments using the single factor test, extraction conditions and levels were selected for orthogonal experiments. The experimental runs and visual analysis of the orthogonal experiments are presented in Table 2. The extraction yields were $2.9-6.7 \%$. In the current study, collaborations amongst the variables were not integrated in the matrix. We focused on the major effects of the five utmost imperative factors. The range analysis specifies that the effect order of the five factors on the extracting ratio of DSEO is $D>A>E>B>C$. In other words, the supreme effect factor is the extraction time, followed by the particle size, the $\mathrm{CO}_{2}$ flow, the extraction temperature, and lastly the extraction pressure. The data provided in Table 2 show that the sixth experimental combination gave a highest DSEO yield of $6.7 \%$. The best extraction conditions were an extraction time of $120 \mathrm{~min}$, particle size of 60 mesh, $\mathrm{CO}_{2}$ flow of $25 \mathrm{~L} / \mathrm{h}$, temperature of $40{ }^{\circ} \mathrm{C}$ and extraction pressure of $20 \mathrm{MPa}$.

\section{Components of DSEO}

The acquired extract samples were injected into GC-MS. Figure 2 demonstrates the GC-MS total ion chromatograms of DSEO, and the relative contents of each component are shown in Table 3. We recognized 38 components of the essential oil, which accounted for $96.84 \%$ of the total oil. The primary composites in DSEO were D-Carvone (40.36\%), D-Limonene (19.31\%),
Apiol (17.50 \%), a-pinene (6.43 \%), 9octadecenoic acid $(9.00 \%)$ as well as 9,12 Octadecadienoic acid $(2.44 \%)$ followed by $n$ Hexadecanoic acid $(1.61 \%)$ and cyclohexanone $(1.56 \%)$ (Table 3$)$. Compared to previous studies, the oil showed some differences in composition [14]. These differences may be due to different parts of dill, different geographic origins, seasonal variation, treatments prior to isolation, and isolation procedures [1].

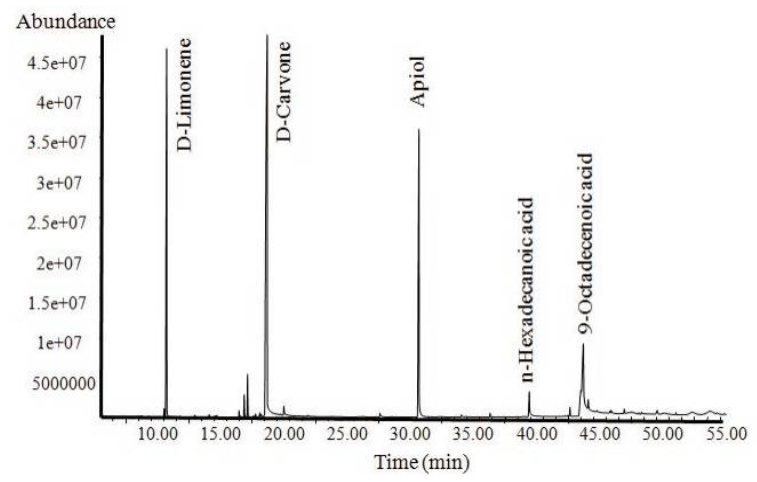

Figure 2: The GC-MS total ion chromatograms of DSEO

\section{CONCLUSION}

With the method of supercritical $\mathrm{CO}_{2}$ extraction, the optimal conditions of extracting essential oil from dill seed are: extraction time of $120 \mathrm{~min}$, particle size 60 mesh, $\mathrm{CO}_{2}$ flow $25 \mathrm{~L} / \mathrm{h}$, temperature $40^{\circ} \mathrm{C}$, and pressure $20 \mathrm{MPa}$. Under these conditions, essential oil yield is $6.7 \%$.

Table 2: Visual analysis of the orthogonal experiment

\begin{tabular}{|c|c|c|c|c|c|c|}
\hline Run & $\begin{array}{c}\text { Particle size } \\
\text { (mesh) } \\
\text { A }\end{array}$ & $\begin{array}{c}\text { Temperature } \\
\left({ }^{\circ} \mathrm{C}\right) \\
\text { B }\end{array}$ & $\begin{array}{c}\text { Pressure } \\
\text { (MPa) } \\
\text { C }\end{array}$ & $\begin{array}{c}\text { Time } \\
\text { (min) } \\
\text { D }\end{array}$ & $\begin{array}{c}\mathrm{CO}_{2} \text { flow } \\
\text { (L/h) } \\
\text { E }\end{array}$ & $\begin{array}{l}\text { Yield of oil } \\
\text { extract (\%) }\end{array}$ \\
\hline 1 & 1 & 1 & 1 & 1 & 1 & 3 \\
\hline 2 & 1 & 2 & 2 & 2 & 2 & 4.5 \\
\hline 3 & 1 & 3 & 3 & 3 & 3 & 5.3 \\
\hline 4 & 1 & 4 & 4 & 4 & 4 & 5.3 \\
\hline 5 & 2 & 1 & 2 & 3 & 4 & 6.3 \\
\hline 6 & 2 & 2 & 1 & 4 & 3 & 6.7 \\
\hline 7 & 2 & 3 & 4 & 1 & 2 & 4.5 \\
\hline 8 & 2 & 4 & 3 & 2 & 1 & 5.8 \\
\hline 9 & 3 & 1 & 3 & 4 & 2 & 5.7 \\
\hline 10 & 3 & 2 & 4 & 3 & 1 & 5.3 \\
\hline 11 & 3 & 3 & 1 & 2 & 4 & 5.3 \\
\hline 12 & 3 & 4 & 2 & 1 & 3 & 3.7 \\
\hline 13 & 4 & 1 & 4 & 2 & 3 & 3.9 \\
\hline 14 & 4 & 2 & 3 & 1 & 4 & 2.9 \\
\hline 15 & 4 & 3 & 2 & 4 & 1 & 4.6 \\
\hline 16 & 4 & 4 & 1 & 3 & 2 & 4.4 \\
\hline $\mathrm{K} 1$ & 4.525 & 4.725 & 4.850 & 3.525 & 4.675 & \\
\hline $\mathrm{K} 2$ & 5.825 & 4.850 & 4.775 & 4.875 & 4.775 & \\
\hline K3 & 5.000 & 4.925 & 4.925 & 5.325 & 4.900 & \\
\hline K4 & 3.950 & 4.800 & 4.750 & 5.575 & 4.950 & \\
\hline Range & 1.875 & 0.200 & 0.175 & 2.050 & 0.275 & \\
\hline
\end{tabular}


Table 3: Chemical composition of DSEO

\begin{tabular}{|c|c|c|c|}
\hline No. & Retention time (min) & the relative content (\%) & Library/ID \\
\hline 1 & 9.8377 & 0.0413 & (1R)-2,6,6-Trimethylbicyclo[3.1.1]hept-2-ene \\
\hline 2 & 11.2281 & 0.0589 & Bicyclo[3.1.0]hexane, 4-methylene-1-(1-methylethyl)- \\
\hline 3 & 11.3483 & 0.0547 & beta.-Pinene \\
\hline 4 & 11.8461 & 0.0536 & beta.-Myrcene \\
\hline 5 & 13.0763 & 0.3425 & p-Cymene \\
\hline 6 & 13.2823 & 19.3122 & D-Limonene \\
\hline 7 & 14.3466 & 0.0398 & gamma.-Terpinene \\
\hline 8 & 15.4967 & 0.0579 & o-Isopropenyltoluene \\
\hline 9 & 17.0931 & 0.0502 & Limonene oxide, cis- \\
\hline 10 & 17.2591 & 0.0778 & Limonene oxide, trans- \\
\hline 11 & 19.01 & 0.235 & 3,6-Dimethyl-2,3,3a,4,5,7a-hexahydrobenzofuran \\
\hline 12 & 19.1244 & 0.0413 & trans-p-mentha-1(7),8-dien-2-ol \\
\hline 13 & 19.6795 & 1.5608 & Cyclohexanone, 2-methyl-5-(1-methylethenyl)-, trans- \\
\hline 14 & 20.1429 & 0.0906 & Neodihydrocarveol \\
\hline 15 & 20.3089 & 0.1858 & 2-Cyclohexen-1-ol, 2-methyl-5-(1-methylethenyl)-, cis- \\
\hline 16 & 20.6465 & 0.2637 & $\begin{array}{c}\text { Cyclohexanol, 2-methyl-5-(1-methylethenyl)-, } \\
\text { (1.alpha.,2.beta.,5.alpha.)- }\end{array}$ \\
\hline 17 & 20.7609 & 0.138 & 2-Cyclohexen-1-ol, 2-methyl-5-(1-methylethenyl)-, cis- \\
\hline 18 & 21.2301 & 40.3562 & D-Carvone \\
\hline 19 & 22.5405 & 0.5993 & Anethole \\
\hline 20 & 24.4173 & 0.1275 & 1,2-Cyclohexanediol,1-methyl-4-(1-methylethenyl)- \\
\hline 21 & 30.1392 & 0.2612 & 1,3-Benzodioxole,4-methoxy-6-(2-propenyl)- \\
\hline 22 & 33.2176 & 17.5025 & Apiol \\
\hline 23 & 41.9436 & 1.6149 & n-Hexadecanoic acid \\
\hline 24 & 44.9935 & 0.0458 & 9,12-Octadecadienoic acid (Z,Z)-, methyl ester \\
\hline 25 & 45.1537 & 0.4019 & 6-Octadecenoic acid, methyl ester, (Z)- \\
\hline 26 & 46.0177 & 2.438 & 9,12-Octadecadienoic acid (Z,Z)- \\
\hline 27 & 46.218 & 9.0039 & 9-Octadecenoic acid, (E)- \\
\hline 28 & 46.4984 & 0.1573 & 6-Octadecenoic acid \\
\hline 29 & 46.6013 & 0.8815 & Octadecanoic acid \\
\hline 30 & 47.3051 & 0.1156 & 9-Octadecenoic acid, (E)- \\
\hline 31 & 48.3179 & 0.0857 & Isopropyl linoleate \\
\hline 32 & 48.4267 & 0.1489 & 2-Methyl-Z,Z-3,13-octadecadienol \\
\hline 33 & 50.6067 & 0.0519 & 9,17-Octadecadienal, (Z)- \\
\hline 34 & 50.8184 & 0.1129 & Eicosanoic acid \\
\hline 35 & 52.598 & 0.0564 & (R)-(-)-14-Methyl-8-hexadecyn-1-ol \\
\hline 36 & 53.5307 & 0.0928 & Heptadecane \\
\hline 37 & 55.8995 & 0.1227 & 9,19-Cyclolanost-25-en-3-ol, 24-methyl-, (3.beta.,24S)- \\
\hline 38 & 57.33 & 0.0624 & 7-Pentadecyne \\
\hline
\end{tabular}

The findings of this study can be used for process advancement of pilot-scale extraction of DSEO from the seed as well as from similar or related materials. A total of 38 components of the DSEO have been recognized by GC-MS. DCarvone could not previously be evaluated by only GC-MS.

\section{DECLARATIONS}

\section{Acknowledgement}

This work was supported by the National Science Foundation for Post-doctoral Scientists of China (no. 2018M632768) and the Key scientific and technological projects of Henan Province (nos.
172102310240 and 18A550005). The various support is gratefully acknowledged.

\section{Conflict of interest}

No conflict of interest is associated with this work.

\section{Contribution of authors}

We declare that this work was done by the authors named in this article and all liabilities pertaining to claims relating to the content of this article will be borne by the authors. 


\section{Open Access}

This is an Open Access article that uses a funding model which does not charge readers or their institutions for access and distributed under the terms of the Creative Commons Attribution License (http://creativecommons.org/licenses/by/ 4.0) and the Budapest Open Access Initiative (http://www.budapestopenaccessinitiative.org/rea d), which permit unrestricted use, distribution, and reproduction in any medium, provided the original work is properly credited.

\section{REFERENCES}

1. Chahal KK, Monika, Kumar A, Bhardwaj U, Kaur R. Chemistry and biological activities of Anethum graveolens L. (dill) essential oil: A review. Journal of Pharmacognosy and Phytochemistry 2017; 6: 295-306.

2. Lisiewska $Z$, Kmiecik W, Korus A. Content of vitamin C, carotenoids, chlorophylls and polyphenols in green parts of dill (Anethum graveolens L.) depending on plant height. Journal of Food Composition and Analysis 2006; 19: 134-140.

3. Jana S, Shekhawat GS. Anethum graveolens: An Indian traditional medicinal herb and spice. Pharmacognosy Reviews 2010; 4: 179-184.

4. Fatima RJ, Avelina FV, Nelly RC, Enrique P, Aurelio LM. Essential Oils: Antimicrobial Activities, Extraction Methods, and Their Modeling. Food Engineering Reviews 2015; 7: 275-297.

5. Chatterjee, Ghosh D, Ghosh PK, Bhattacharjee S, Paramita. Supercritical carbon dioxide extraction of eugenol from tulsi leaves: Process optimization and packed bed characterization. Chemical Engineering Research and Design 2017; 118:94-102.

6. Shrigod NM, Swami Hulle NR, Prasad RV. Supercritical fluid extraction of essential oil from mint leaves (mentha spicata): Process optimization and its quality evaluation. Journal of Food Process Engineering 2017; 40: e12488.
7. Ixtaina VY, Mattea, $F$, Cardarelli DA, Mattea MA, Nolasco SM, Tomás MC. Supercritical Carbon Dioxide Extraction and Characterization of Argentinean Chia Seed Oil. Journal of the American Oil Chemists' Society 2011; 88: 289-298.

8. Jokic $S$, Jerkovic I, Rajic $M$, Aladic $K$, Bilic $M$, idovic $S$. $\mathrm{SC}-\mathrm{CO}_{2}$ extraction of Vitex agnus-castus L. fruits: The influence of pressure, temperature and water presoaking on the yield and GC-MS profiles of the extracts in comparison to the essential oil composition. Journal of Supercritical Fluids 2017; 123: 50-57.

9. Dima $C$, Ifrim $G A$, Coman $G$, Alexe $P$, Dima $S$. Supercritical $\mathrm{CO}_{2}$ Extraction and Characterization of Coriandrum Sativum L. Essential Oil. Journal of Food Process Engineering 2016; 39: 204-211.

10. Wei ZJ, Liao AM, Zhang HX, Liu J, Jiang ST. Optimization of supercritical carbon dioxide extraction of silkworm pupal oil applying the response surface methodology. Bioresource Technology 2009; 100: 42144219.

11. Grosso C, Ferraro V, Figueiredo AC, Barroso, JG, Coelho JA, Palavra AM. Supercritical carbon dioxide extraction of volatile oil from Italian coriander seeds. Food Chemistry 2008; 111: 197-203.

12. Suetsugu T, Tanaka M, Iwai H, Matsubara T, Kawamoto, Y, Saito C, Sasaki Y, Hoshino M, Quitain AT, Sasaki M, et al. Supercritical $\mathrm{CO}_{2}$ extraction of essential oil from Kabosu (Citrus sphaerocarpa Tanaka) peel. Flavour 2013; 2: 18.

13. Dong D. Wang $H, X u F, X u C$, Shao X, Li H. Supercritical Carbon Dioxide Extraction, Fatty Acid Composition, Oxidative Stability, and Antioxidant Effect of Torreya grandis Seed Oil. Journal of the American Oil Chemists' Society 2014; 91: 817-825.

14. Ma B, Ban $X$, Huang B, He J, Tian J, Zeng $H$, Chen $Y$, Wang $Y$. Interference and Mechanism of Dill Seed Essential Oil and Contribution of Carvone and Limonene in Preventing Sclerotinia Rot of Rapeseed. PLoS One 2015; $p$ e0131733. 